\title{
Stereoselective Bioreduction of Telluro-acetophenones to Optically Active Hydroxy Tellurides
}

\author{
Pamela Taisline Bandeira, ${ }^{[a],[b]}$ Vicente Gotor-Fernández, ${ }^{[b]}$ and Leandro Piovan ${ }^{*[a]}$
}

\begin{abstract}
Organotellurium compounds exhibit a broad range of useful applications in organic synthesis, materials science and medicinal chemistry fields. Despite their increasing applicability, the synthesis of enantiomerically pure organotellurium compounds remains nowadays scarcely reported in the literature. Herein, the chemical synthesis and biocatalyzed reductions of a set of telluro-acetophenones using both $(R)$ and $(S)$-selective alcohol dehydrogenases (ADHs) is described for the first time, obtaining enantiomerically enriched hydroxy tellurides with excellent selectivities under very mild reaction conditions. On the one hand, enantiopure para-substiuted (S)-hydroxy tellurides were obtained using the Ras-ADH (77-95\% conversion) and ADH-A (52$75 \%$ ), the ADH-A leading to the enantiopure (S)-hydroxy tellurides substituted at the meta-position (69-75\%). On the other hand, the evo1.1.200 displayed high selectivity towards the preparation of optically alcohols with substitutions at the para-position of the aromatic ring (60-68\% conversion and $92-97 \%$ ee), while the Lb-ADH led to the best results when reducing bulky ketones at the meta-position (79-82\% conversion and $88-99 \%$ ee).
\end{abstract}

\section{Introduction}

The chemistry of tellurium (Te) has experienced great progress in recent decades $^{1}$ presenting Te-containing compounds as versatile reagents and synthons for many synthetic purposes, including carbon-carbon bond formation reactions, ${ }^{2}$ and a variety of functional group interconversions. ${ }^{3}$ Organotellurium substances also have important and useful applications in materials science, ${ }^{4}$ as well as displaying remarkable pharmacological profiles ${ }^{5}$ with a broad range of biological activities. ${ }^{6}$

Despite their synthetic and biological importance, especially when considering their chiral versions, few efforts have been focused on the synthesis of enantiomerically pure organotellurium compounds. In contrast to the more deeply studied organoselenium analogues, ${ }^{7}$ robust and straightforward routes towards optically active organotellurium compounds remain nowadays scarcely reported in the literature. To the best of our knowledge, their asymmetric syntheses are limited to the enzymatic kinetic resolutions (EKR) of aliphatic-,${ }^{8}$ vinyl-,${ }^{9}$ and $\beta$ - hydroxy ${ }^{10}$ organotellurides successfully applied as chiral building blocks (Figure 1) and the development of non stereoselective approaches when starting from optically active precursors of the desired organotellurium compounds used as antioxidant agents, and precursors of enzymatic inhibitors and antitumor agents (Figure 1). ${ }^{11}$

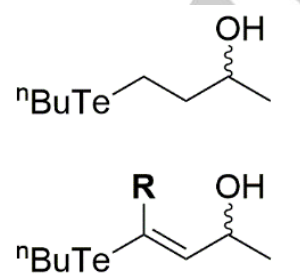<smiles>CC(C)c1ccccc1[TeH2]c1ccccc1</smiles><smiles>[X][Te]([Y])(Br)c1ccccc1C(C)OC</smiles>

Antioxidant

Enzyme inhibitors

Building blocks (GPX-like activity) Antitumor agents

Figure 1. Representative (chiral) Te-containing compounds with synthetic applications and biological properties.

Nowadays, biocatalysis is a consolidated technology in organic synthesis mainly due to the high level of stereoselectivity displayed by enzymes under mild reaction conditions and the wide number of existing enzymes able to catalyze multiple transformations. ${ }^{12}$ Among asymmetric biotransformations, the stereoselective reduction of carbonyl compounds catalyzed by alcohol dehydrogenases (ADHs, E.C.1.1.1.1, also known as ketoreductases or carbonyl reductases) provides an elegant manner to produce optically active alcohols by using purified or whole-cell enzyme forms. ${ }^{13}$ Interestingly, the versatility of ADHs has been widely demonstrated for the stereoselective reduction of a broad range of prochiral carbonyl compounds, including $\beta$ nitroketones, ${ }^{14} \beta$-keto amides ${ }^{15}$ or ketones containing halogens, ${ }^{16}$ sulfur, ${ }^{17}$ boron ${ }^{18}$ and others functionalities. ${ }^{19}$

Hence, we have focused in the chemical synthesis and later development of ADH-catalyzed bioreductions of a set of telluroacetophenones using both $(R)$ - and $(S)$-selective ADHs, which could lead us to the development of a straightforward strategy towards enantiomerically enriched hydroxy tellurides under very mild reaction conditions in aqueous medium.

\section{Results and Discussion}

A series of prochiral telluro-acetophenones $\mathbf{3 a - g}$ bearing variable alkyl aliphatic chains $\left(\mathrm{R}=\mathrm{Me}, \mathrm{Et},{ }^{n} \mathrm{Pr}\right.$ and ${ }^{n} \mathrm{Bu}$, Scheme 1) straight linked to the Te atom in meta and para positions was chemically synthetized according to adapted protocols to the ones described in the literature for structurally similar organotellurium compounds. $^{20}$ Firstly, commercially available 3'- and 4'bromoacetophenone were converted into the corresponding acetals 1 using ethylene glycol with 98\% (meta) and 82\% (para) isolated yields. Subsequently, the acetals were employed as precursors for Grignard reagents to provide ditellurides 2 in $77 \%$ 
(meta) and $79 \%$ (para) isolated yields after the oxidative step. ${ }^{20}$ Finally, sodium borohydride was used for the Te-Te bond cleavage, followed by alkylation and deprotection sequential steps led to telluroketones $3 \mathrm{a}-\mathrm{g}$ in yields ranging from $35 \%$ to $55 \%$. By using this strategy five novel telluro-acetophenones containing methyl (3a), ethyl (3b and $\mathbf{3 e}$ ) and $n$-propyl (3c and $\mathbf{3} \mathbf{f}$ ) rests linked to $\mathrm{Te}$ atom were synthesized besides of already known $\mathrm{Te}^{n} \mathrm{Bu}$ ones (3d and $\mathbf{3 g}$ ). For analytical purposes, racemic hydroxy tellurides $\mathbf{4 a - g}$ were prepared in $35-92 \%$ yields by chemical reduction of ketones $\mathbf{3 a - g}$ with sodium borohydride in methanol. Thus, efficient analytical separations were developed using the gas chromatography (GC) technique, before carrying out the stereoselective reductive biotransformations using a variety of made in house and commercially available ADHs.

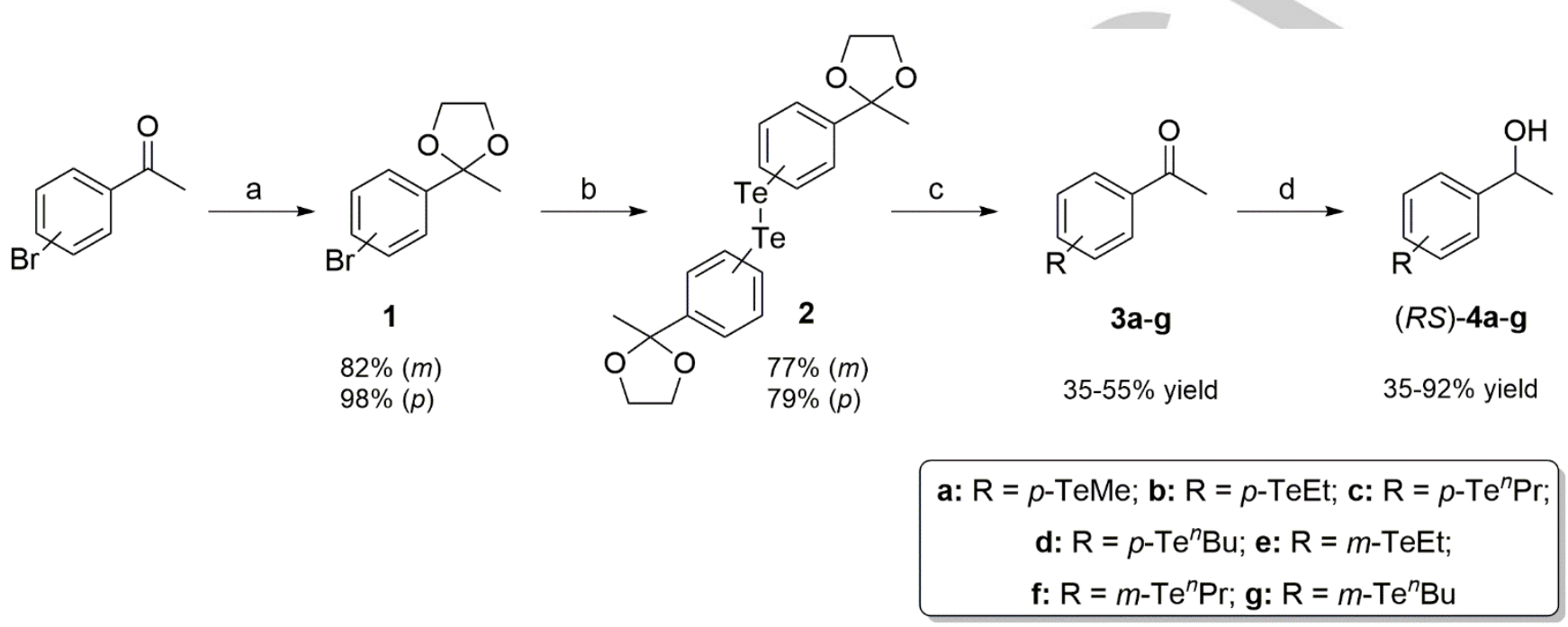

Scheme 1. Synthetic route for telluro-acetophenones $\mathbf{3 a - g}$ and the corresponding racemic hydroxy tellurides $\mathbf{4 a - g}$. Reaction conditions: a) Ethylene glycol, $p$-TsOH, toluene, reflux, $24 \mathrm{~h}\left(82-98 \%\right.$ yield). b) i. Mg, THF, reflux, $3 \mathrm{~h}$; ii. Te, r.t., overnight; iii. $\mathrm{H}_{2} \mathrm{O}$, atmosphere, $1 \mathrm{~h}\left(77-79 \%\right.$ yield). c) i. $\mathrm{RX}\left(\mathrm{R}=\mathrm{Me}\right.$, Et, ${ }^{n} \mathrm{Pr}$, ${ }^{n} \mathrm{Bu}$; $\mathrm{X}=\mathrm{Br}$ or I), $\mathrm{NaBH}_{4}, \mathrm{MeOH}, \mathrm{THF}, 0^{\circ} \mathrm{C}$ to r.t., $10 \mathrm{~min}$; ii. $\mathrm{p}-\mathrm{TsOH}$, acetone, reflux, $1.5 \mathrm{~h}\left(35-55 \%\right.$ yield). d) $\mathrm{NaBH}_{4}, \mathrm{MeOH}^{\circ} 0^{\circ} \mathrm{C}$ to r.t., $2 \mathrm{~h}(35-92 \%$ yield).

Next, the bioreductions of telluro-acetophenones 3a-g were investigated (Table 1) under previously established conditions. ${ }^{21}$ As biocatalysts, lyophilized cells of Escherichia coli (E. coli) overexpressing ADH from Ralstonia species (Ras$\mathrm{ADH}),{ }^{22}$ Lactobacillus brevis (Lb-ADH), ${ }^{23}$ Sphingobium yanoikuyae (Sy-ADH), ${ }^{24}$ Thermoanaerobacter ethanolicus (Tes$\mathrm{ADH}),{ }^{25}$ Thermoanaerobacter species (ADH-T), ${ }^{26}$ Rhodococcus ruber $(\mathrm{ADH}-\mathrm{A})^{27}$ and the commercially available evo $1.1 .200^{28}$ were assayed.

Satisfyingly five out of the seven ADHs were able to catalyze the enantioselective bioreduction of telluroketones $\mathbf{3 a - g}$ to the desired optically active hydroxy tellurides $\mathbf{4 a - g}$, attaining depending on the enzyme choice moderate to excellent selectivities towards the production of $(R)$-alcohols (58->99\% ee), while remarkably the synthesis of enantiopure $(S)$-alcohols $4 \mathbf{a}-\mathbf{g}$ was possible using the appropriate enzyme (Table 1).

Regarding bioreductive reactions of para-substituted telluroketones 3a-d they were achieved in good to excellent extension using the Ras-ADH (77-95\% conversion, entry 1$)$ and the ADH-A (52-75\% conversion, entry 6$)$, obtaining in all cases the (S)-hydroxy tellurides in enantiomerically pure form, meanwhile the Sy-ADH (entry 3) led to modest activity and selectivity values. Interestingly for the Ras-ADH, increasing the alkyl length chain linked to Te atom from ethyl (3b, $\mathrm{R}=p$-TeEt) to butyl (3d, $\left.\mathrm{R}=p-\mathrm{Te}^{n} \mathrm{Bu}\right)$ a decrease in the conversion rates from 95 to $77 \%$ was observed (entry 1 ). An interesting trend was also observed when changing the aromatic pattern substitution from para to meta position, resulting in a significant decrease in activity for the Ras-ADH in the bioreduction of $\mathbf{3 e - g}$ (40-54\% conversion and $72-86 \%$ ee, entry 1 ), while the ADH-A demonstrated its versatility by producing the enantiopure $(S)$-alcohols in $69-75 \%$ conversion (entry 6).

When anti-Prelog enzymes such as the Lb-ADH (entry 2) and the commercially available evo-1.1.200 (entry 7) were employed, the Lb-ADH acted with a moderate to excellent selectivity towards para-substituted acetophenones $(57->99 \%$ ee), reaching a complete selectivity when the bulkier substrate $\mathbf{3 d}$ was considered obtaining the corresponding butyl derivative $\mathbf{4 d}$ in enantiopure form. A similar trend was observed with the evo$1.1 .200(51-60 \%$ conversion and $58-84 \%$ ee), however a notable difference between both enzymes was noticed when facing the meta-substituted ketones $\mathbf{3 e - g}$. In fact, a significant decrease in activity was observed with the $\mathrm{Lb}-\mathrm{ADH}$, while high selectivities and moderate conversions were reached with the evo-1.1-200 (60-68\% conversion and $92-97 \%$ ee) for the production of $(R)-4 \mathbf{e}-$ g.

Finally, a semi-preparative scale ADH-catalysed reduction was carried out employing $100 \mathrm{mg}$ of telluro-acetophenone $\mathbf{3 b}$ ( $\mathrm{R}$ $=p$-TeEt) employing Ras-ADH as biocatalyst. After $24 \mathrm{~h}$, the conversion rate reached $84 \%$, obtaining the optically active hydroxy telluride $(S)-(-)-\mathbf{4 b}$ with $42 \%$ of isolated yield and $>99 \%$ ee $\left.\left([\alpha]_{\mathrm{D}}{ }^{20}=-10.2\left(\mathrm{C}=2.0, \mathrm{CHCl}_{3}\right)\right]\right)$ after silica gel column 
purification, demonstrating the robustness of the bioreduction process.

Table 1. Bioreduction of telluro-acetophenones 3a-g catalyzed by alcohol dehydrogenases (ADHs)<smiles>[R][X]c1ccccc1C(C)=O</smiles>

3a-g

\author{
$\mathrm{ADH}, \mathrm{NAD}(\mathrm{P})^{+}$ \\ Cofactor regeneration system \\ $50 \mathrm{mM}$ Tris $\mathrm{HCl}$ buffer $\mathrm{pH} 7.5$ \\ $30{ }^{\circ} \mathrm{C}, 250 \mathrm{rpm}, 24 \mathrm{~h}$
}<smiles>[R][X]c1ccccc1C(C)O</smiles>

$(R)$ or $(S)-4 a-g$

\begin{tabular}{|c|c|c|c|c|c|c|c|c|c|c|c|c|c|c|c|}
\hline Entry & $\begin{array}{c}\text { Alcohol } \\
\text { dehydrogenase }\end{array}$ & \multicolumn{2}{|c|}{$\begin{array}{c}\mathbf{4 a} \\
(\mathrm{R}=p-\mathrm{TeMe})\end{array}$} & \multicolumn{2}{|c|}{$\begin{array}{c}\mathbf{4 b} \\
(\mathrm{R}=p-\mathrm{TeEt})\end{array}$} & \multicolumn{2}{|c|}{$\begin{array}{c}\mathbf{4 c} \\
\left(\mathrm{R}=p-\mathrm{T} \mathrm{e}^{n} \mathrm{Pr}\right)\end{array}$} & \multicolumn{2}{|c|}{$\begin{array}{c}\mathbf{4 d} \\
\left(\mathrm{R}=p-\mathrm{Te}^{n} \mathrm{Bu}\right)\end{array}$} & \multicolumn{2}{|c|}{$(\mathrm{R}=m-\mathrm{e}$-TeEt $)$} & \multicolumn{2}{|c|}{$\begin{array}{c}\mathbf{4 f} \\
\left(\mathrm{R}=m-\mathrm{T} \mathrm{e}^{\mathrm{n}} \mathrm{Pr}\right)\end{array}$} & \multicolumn{2}{|c|}{$\begin{array}{c}\mathbf{4 g} \\
(\mathrm{R}=m- \\
\left.\mathrm{Te}^{n} \mathrm{Bu}\right)\end{array}$} \\
\hline 1 & E. coli/Ras-ADH & 92 & $>99(S)$ & 95 & $>99(S)$ & 88 & $>99(S)$ & 77 & $>99(S)$ & 54 & $77(S)$ & 48 & $72(S)$ & 40 & $\begin{array}{l}86 \\
(S)\end{array}$ \\
\hline 2 & E. coli/Lb-ADH & 44 & $57(R)$ & 69 & $84(R)$ & 79 & $88(R)$ & 82 & $>99(R)$ & 32 & $97(R)$ & 13 & n.d. & 7 & n.d. \\
\hline 3 & E. coli/Sy-ADH & 56 & $46(S)$ & 62 & $52(S)$ & 54 & $63(S)$ & 67 & $95(S)$ & 68 & $58(S)$ & 58 & $80(S)$ & 56 & $\begin{array}{l}71 \\
(S)\end{array}$ \\
\hline 4 & E. coli/TeS-ADH & $<5$ & n.d. & 17 & n.d. & 13 & n.d. & $<5$ & n.d. & 9 & n.d. & $<5$ & n.d. & $<5$ & n.d. \\
\hline 5 & E. coli/ADH-T & $<5$ & n.d. & 19 & n.d. & 22 & n.d. & $<5$ & n.d. & 8 & n.d. & $<5$ & n.d. & $<5$ & n.d. \\
\hline 6 & E. coli/ADH-A & 52 & $>99(S)$ & 69 & $>99(S)$ & 72 & $>99(S)$ & 75 & $>99(S)$ & 75 & $\begin{array}{l}>99 \\
(S)\end{array}$ & 75 & $>99(S)$ & 69 & $\begin{array}{l}>99 \\
(S)\end{array}$ \\
\hline 7 & evo-1.1.200 & 60 & $58(R)$ & 53 & $67(R)$ & 51 & $73(R)$ & 52 & $84(R)$ & 68 & $97(R)$ & 64 & $96(R)$ & 60 & $\begin{array}{l}92 \\
(R)\end{array}$ \\
\hline
\end{tabular}

a Conversion values were determined by GC. ${ }^{b}$ Enantiomeric excess values were determined by GC after removed the alkyl-tellurium moiety ("TeR") with 'BuLi. Absolute configurations appear in brackets. n.d. not determined due to the low conversion rates.

\section{Conclusions}

In summary, a series of telluro-acetophenones, including five novels ones, has been successfully reduced to the corresponding optically active hydroxy tellurides employing ADH-catalyzed bioreduction processes. For the production of enantiopure parasubstituted $(S)$-hydroxy tellurides, the best results were obtained using the Ras-ADH and ADH-A, the latest being also capable to give access to the enantiopure $(S)$-hydroxy tellurides when the substitution was present at the meta-position. In a complementary approach, the Lb-ADH and the evo-1.1.200 allowed the preparation of the $(R)$-alcohols displaying the best selectivities with the $\mathrm{Lb}-\mathrm{ADH}$ in the bioreduction of the most bulkier substrates, while the evo-1.1.200 demonstrated its potential in the preparation of optically alcohols with substitutions at the paraposition of the aromatic ring.

Overall, this is the first report of ADHs-catalyzed reduction of Te-containing carbonyl substrates, demonstrating that the biocatalytic reduction of prochiral telluroketones mediated by $\mathrm{ADHs}$ is an efficient and powerful approach to produce optically active hydroxy tellurides, being possible the isolation of the (S)or $(R)$-enantiomers depending on the enzyme of choice.

\section{Experimental Section}

Chemical reagents for the synthesis of ketones 3a-g and alcohols $4 a$ $\mathrm{g}$ were purchased from Sigma-Aldrich. For the bioreduction experiments, D-glucose, NADH and NADPH were also acquired from Sigma-Aldrich, while glucose dehydrogenase (GDH-105) was obtained from Codexis Inc. and evo-1.1.200 from Evoxx Technologies GmbH. Made in house ADHs were overexpressed in E. coli: Ralstonia species (Ras-ADH), Sphingobium yanoikuyae (Sy-ADH), Thermoanaerobacter species (ADH-T), Lactobacillus brevis (Lb-ADH), Thermoanaerobacter ethanolicus (TeS$\mathrm{ADH}$ ) and Rhodococcus ruber (ADH-A).

Nuclear magnetic resonance (NMR) spectra $\left({ }^{1} \mathrm{H}\right.$ and $\left.{ }^{13} \mathrm{C}\right)$ were recorded on a Bruker AV300 MHz spectrometer. ${ }^{125} \mathrm{Te}$ NMR spectra were recorded on a Bruker Avance III at 9.4 T $\left(400.13 \mathrm{MHz}\right.$ for ${ }^{1} \mathrm{H}$ NMR and 126.24 for ${ }^{125} \mathrm{Te} \mathrm{NMR}$ ) and the chemical shifts for ${ }^{125} \mathrm{Te}$ NMR were registered relative to an external standard diphenyl ditelluride $\left(\mathrm{Ph}_{2} \mathrm{Te}\right)$ a $\delta=422 \mathrm{ppm}$. All chemical shifts $(\delta)$ are given in parts per million (ppm). Gas chromatography (GC) analyses were performed on an Agilent HP6890 GC chromatograph equipped with FID detector. Conversion rates measurements were performed on non-chiral GC column DB-1701 (30 m 
$x \quad 0.25 \mathrm{~mm}, 0.25 \mu \mathrm{m})$, while for the enantiomeric excess values determination chiral GC column Chirasil ß-Dex $(25 \mathrm{~m} \times 0.25 \mathrm{~mm}, 0.25 \mu \mathrm{m})$ were required. Melting points were measured in a Stuart apparatus SMP3 (Bibby Sterilin, Staffordshire, UK) introducing the samples in open capillary tubes and the measurements are uncorrected. Optical rotation measurement was performed at $590 \mathrm{~nm}$ on Autopol IV Automatic polarimeter (Rudolph Research Analytical, Hackettstown, NJ, USA). Thinlayer chromatography (TLC) analyses were conducted with Merck Silica Gel 60 F254 precoated plates and visualized with UV, potassium permanganate and vanillin stain. Column chromatographies were performed using silica gel 60 (230-240 mesh)

\section{General procedures for the chemical synthesis of ketones 3a-g and alcohols 4a-g}

\section{Acetalization of 3'- and 4'-bromoacetophenones ${ }^{20}$}

A mixture of the corresponding bromoacetophenone $(5.98 \mathrm{~g}, 25.0 \mathrm{mmol})$, ethylene glycol ( $15 \mathrm{~mL}, 250.0 \mathrm{mmol}), p-\mathrm{TsOH}(0.25 \mathrm{mg}, 1.50 \mathrm{mmol})$ and anhydrous toluene $(150 \mathrm{~mL})$ was stirred and heated under reflux for $24 \mathrm{~h}$. Water formed during the reaction (about $0.5 \mathrm{~mL}$ ) was removed using a Dean-Stark trap. The reaction mixture was cooled and extracted with ethyl acetate $(3 \times 50 \mathrm{~mL})$, and the combined organic phase sequentially washed with a $\mathrm{NaHCO}_{3}$ saturated aqueous solution $(30 \mathrm{~mL})$, water $(30 \mathrm{~mL})$ and brine $\left(30 \mathrm{~mL}\right.$ ). The resulting organic layer was dried over $\mathrm{Na}_{2} \mathrm{SO}_{4}$, filtered and concentrated under reduced pressure, affording the corresponding dioxolanes 1 .

2-(4-Bromophenyl)-2-methyl-1,3-dioxolane. White crystals, $82 \% . R$ (20\% EtOAc/hexane): $0.64 ;{ }^{1} \mathrm{H} \mathrm{NMR}\left(\mathrm{CDCl}_{3}, 300.13 \mathrm{MHz}\right): \delta=1.63(\mathrm{~s}, 3 \mathrm{H})$, 3.71-3.78 (m, 2H), 4.00-4.07 (m, 2H), $7.35\left(\mathrm{dd}, 2 \mathrm{H},{ }^{3} \mathrm{JH}_{\mathrm{H}, \mathrm{H}}=8.7 \mathrm{~Hz},{ }^{4} \mathrm{JH}, \mathrm{H}=\right.$ $1.9 \mathrm{~Hz}), 7.46\left(\mathrm{dd}, 2 \mathrm{H},{ }^{3} \mathrm{~J}_{\mathrm{H}, \mathrm{H}}=8.7 \mathrm{~Hz}\right.$ and $\left.{ }^{4} \mathrm{~J}_{\mathrm{H}, \mathrm{H}}=1.9 \mathrm{~Hz}\right) \mathrm{ppm}$.

2-(3-Bromophenyl)-2-methyl-1,3-dioxolane. Colorless oil, $98 \%$. $R_{f}(20 \%$ EtOAc/hexane): 0.61. ${ }^{1} \mathrm{H}$ NMR $\left(\mathrm{CDCl}_{3}, 300.13 \mathrm{MHz}\right): \delta=1.62(\mathrm{~s}, 3 \mathrm{H})$, $3.70-3.78(\mathrm{~m}, 2 \mathrm{H}), 3.99-4.08(\mathrm{~m}, 2 \mathrm{H}), 7.20\left(\mathrm{t}, 1 \mathrm{H},{ }^{3} \mathrm{~J}_{\mathrm{H}, \mathrm{H}}=7.8 \mathrm{~Hz}\right), 7.41-$ $7.46(\mathrm{~m}, 2 \mathrm{H}), 7.63-7.65(\mathrm{~m}, 1 \mathrm{H}) \mathrm{ppm}$.

\section{Synthesis of diaryl ditellurides $\mathbf{2}^{20}$}

A suspension of magnesium $(0.53 \mathrm{~g}, 22.0 \mathrm{mmol})$ in anhydrous THF (40 $\mathrm{mL}$ ) was added to a solution of the corresponding 2-(bromophenyl)-2methyl-1,3-dioxolane $(\mathbf{1}, 4.86 \mathrm{~g}, 20.0 \mathrm{mmol})$ in anhydrous THF $(10 \mathrm{~mL})$ under nitrogen atmosphere. The mixture was refluxed for $3 \mathrm{~h}$ and after this time, the reaction was left to warm until room temperature. At this point, elemental tellurium $(20.0 \mathrm{mmol})$ was added in one-portion and kept under stirring overnight. The solution was cooled to $0^{\circ} \mathrm{C}$ and water $(30 \mathrm{~mL})$ was added dropwise. The crude reaction was filtered through a celite pad and washed exhaustively with $\mathrm{CH}_{2} \mathrm{Cl}_{2}(3 \times 50 \mathrm{~mL})$. The resulting organic phase was finally washed with brine $(50 \mathrm{~mL})$, dried over $\mathrm{Na}_{2} \mathrm{SO}_{4}$, filtered and concentrated under reduced pressure, isolating the corresponding diaryl ditellurides 2 in satisfactory purity to be used in the next step without further purification.

1,2-bis[4-(2-Methyl-1,3-dioxolan-2-yl)phenyl]ditellane. Red powder, $77 \%$. Mp: $139-141{ }^{\circ} \mathrm{C}$. $R_{f}\left(20 \%\right.$ EtOAc/hexane): $0.33 .{ }^{1} \mathrm{H}$ NMR $\left(\mathrm{CDCl}_{3}\right.$, $300.13 \mathrm{MHz}): \delta=1.63(\mathrm{~s}, 3 \mathrm{H}), 3.76-3.77(\mathrm{~m}, 2 \mathrm{H}), 4.02-4.03(\mathrm{~m}, 2 \mathrm{H}), 7.30$ (dd, $2 \mathrm{H},{ }^{3}{ }^{H}$ H,H $\left.=8.4,{ }^{4} \mathrm{~J}_{H, H}=1.8\right), 7.77\left(\mathrm{dd}, 2 \mathrm{H},{ }^{3} \mathrm{~J}_{\mathrm{H}, H}=8.4 \mathrm{~Hz},{ }^{4} \mathrm{~J}_{H, H}=1.8\right.$ $\mathrm{Hz}) ;{ }^{13} \mathrm{C} \mathrm{NMR}\left(\mathrm{CDCl}_{3}, 75.5 \mathrm{MHz}\right): \delta=27.6,64.5,107.2,108.5,125.2,126.3$ 128.2, 137.3, $143.6 \mathrm{ppm} ;{ }^{125} \mathrm{Te}$ NMR (126.2 MHz): $\delta=408 \mathrm{ppm}$.

1,2-bis[3-(2-Methyl-1,3-dioxolan-2-yl)phenyl]ditellane. Red powder, $79 \%$. Mp: $140-143{ }^{\circ} \mathrm{C}$. $R_{f}\left(20 \%\right.$ EtOAc/hexane): $0.41 .{ }^{1} \mathrm{H} \mathrm{NMR}\left(\mathrm{CDCl}_{3}\right.$
$300.13 \mathrm{MHz}): \delta=1.64(\mathrm{~s}, 3 \mathrm{H}), 3.72-3.82(\mathrm{~m}, 2 \mathrm{H}), 4.00-4.10(\mathrm{~m}, 2 \mathrm{H}), 7.18$ $\left(\mathrm{t}, 1 \mathrm{H},{ }^{3} \mathrm{~J}_{\mathrm{H}, H}=7.6\right), 7.34\left(\mathrm{t}, 1 \mathrm{H},{ }^{3} \mathrm{~J}_{\mathrm{H}, H}=8.0 \mathrm{~Hz}\right), 7.76\left(\mathrm{~d}, 1 \mathrm{H},{ }^{3} \mathrm{~J}_{\mathrm{H}, H}=7.6 \mathrm{~Hz}\right)$, $7.97(\mathrm{~s}, 1 \mathrm{H}) \mathrm{ppm} ;{ }^{13} \mathrm{C} \mathrm{NMR}\left(\mathrm{CDCl}_{3}, 75.5 \mathrm{MHz}\right): \delta=27.5,64.4,107.8,108.3$, 125.2, 129.1, 134.2, 137.0, 144.2 ppm; ${ }^{125} \mathrm{Te}$ NMR (126.2 MHz): $\delta=426$ ppm.

Synthesis of telluroketones $\mathbf{3 a - g}$

$\mathrm{MeOH}(2 \mathrm{~mL}$ ) was added dropwise to a suspension of the corresponding diacetal ditelluride $2(0.58 \mathrm{mg}, 1.0 \mathrm{mmol})$, the corresponding alkyl halide $(3.0 \mathrm{mmol})$ and $\mathrm{NaBH}_{4}(0.11 \mathrm{~g}, 3 \mathrm{mmol})$ in anhydrous THF $(5 \mathrm{~mL})$ under nitrogen atmosphere at $0{ }^{\circ} \mathrm{C}$. The mixture was left to warm until room temperature and stirred for $1 \mathrm{~h}$. After this period unreacted hydride excess was destroyed adding an aqueous $\mathrm{NH}_{4} \mathrm{Cl}$ saturated solution $(5 \mathrm{~mL})$. The mixture was extracted with $\mathrm{CH}_{2} \mathrm{Cl}_{2}(3 \times 15 \mathrm{~mL})$, combining the organic layers that were next washed with brine $(15 \mathrm{~mL})$. The resulting organic phase was dried over $\mathrm{Na}_{2} \mathrm{SO}_{4}$, filtered and concentrated under reduced pressure. The crude product was dissolved in acetone $(15 \mathrm{~mL})$ and $p$ $\mathrm{TsOH}(0.15 \mathrm{mmol})$ was added. The mixture was refluxed for $4 \mathrm{~h}$, and after this time, the solvent was removed under reduced pressure and the reaction crude purified by column chromatography on silica gel $(20 \%$ EtOAc/hexane), affording the corresponding organotellurium ketones $3 \mathrm{a}$ g.

1-[4-(Methyltellanyl)phenyl]ethanone (3a). Yellow powder, 35\%. $R_{f}$ (20\% EtOAc/hexane): 0.43 . IR (NaCl): $v=1217,1366,1580,1670,1738$, $2971 \mathrm{~cm}^{-1} \cdot \mathrm{H}$ NMR $\left(\mathrm{CDCl}_{3}, 300.13 \mathrm{MHz}\right): \delta=2.25(\mathrm{~s}, 3 \mathrm{H}), 2.56(\mathrm{~s}, 3 \mathrm{H})$, $7.64\left(\mathrm{dd}, 2 \mathrm{H},{ }^{3} J_{H, H}=8.6 \mathrm{~Hz},{ }^{4} J_{H, H}=2.0 \mathrm{~Hz}\right), 7.75\left(\mathrm{dd}, 2 \mathrm{H},{ }^{3} J_{H, H}=8.6 \mathrm{~Hz}\right.$, $\left.\left.{ }^{4} \mathrm{~J}_{\mathrm{H}, \mathrm{H}}=2.0 \mathrm{~Hz}\right) \mathrm{ppm} ;{ }^{13} \mathrm{C} \mathrm{NMR}\left(\mathrm{CDCl}_{3}, 75.5 \mathrm{MHz}\right): \delta=\right):-16.3,26.6,121.6$, 128.6, 135.2, 135.8, $197.7 \mathrm{ppm}$; ${ }^{125} \mathrm{Te} \mathrm{NMR}(126.2 \mathrm{MHz}): \delta=343 \mathrm{ppm}$.

1-[4-(Ethyltellanyl)phenyl]ethanone (3b). Pale yellow oil, $55 \%$. $R_{f}(20 \%$ EtOAc/hexane): 0.68. IR ( $\mathrm{NaCl}): v=1263,1580,1674,2816,2916,2954$ $\mathrm{cm}^{-1} .{ }^{1} \mathrm{H}$ NMR $\left(\mathrm{CDCl}_{3}, 300.13 \mathrm{MHz}\right): \delta=1.69\left(\mathrm{t}, 3 \mathrm{H},{ }^{3} \mathrm{JH}_{\mathrm{H}, \mathrm{H}}=7.6 \mathrm{~Hz}\right), 2.57$ $(\mathrm{s}, 3 \mathrm{H}), 2.96\left(\mathrm{q}, 2 \mathrm{H},{ }^{3} \mathrm{JH}_{\mathrm{H}, \mathrm{H}}=7.6 \mathrm{~Hz}\right), 7.74(\mathrm{~m}, 4 \mathrm{H}) \mathrm{ppm} ;{ }^{13} \mathrm{C} \mathrm{NMR}\left(\mathrm{CDCl}_{3}\right.$, $75.5 \mathrm{MHz}$ ): $\delta=0.9,17.3,26.6,120.7,128.7,136.0,136.0,197.8 \mathrm{ppm} ;{ }^{125} \mathrm{Te}$ $\operatorname{NMR}(126.2 \mathrm{MHz}): \delta=541 \mathrm{ppm}$.

1-[4-(Propyltellanyl)phenyl]ethanone (3c). Yellow oil, $53 \%$. $R_{f}(20 \%$ EtOAc/hexane): 0.46. IR ( NaCl): $v=1262,1589,1675,2867,2925,2956$ $\mathrm{cm}^{-1} .{ }^{1} \mathrm{H}$ NMR $\left(\mathrm{CDCl}_{3}, 300.13 \mathrm{MHz}\right): \delta=0.99\left(\mathrm{t}, 3 \mathrm{H},{ }^{3} \mathrm{~J}_{\mathrm{H}, \mathrm{H}}=7.2 \mathrm{~Hz}\right), 1.85$ (sext, $\left.2 \mathrm{H},{ }^{3} J_{H, H}=7.3 \mathrm{~Hz}\right), 2.55(\mathrm{~s}, 3 \mathrm{H}), 2.94\left(\mathrm{t}, 3 \mathrm{H},{ }^{3} \mathrm{~J}_{\mathrm{H}, H}=7.3 \mathrm{~Hz}\right), 7.71(\mathrm{~m}$, 4H) ppm; ${ }^{13} \mathrm{C} \mathrm{NMR}\left(\mathrm{CDCl}_{3}, 75.5 \mathrm{MHz}\right): \delta=11.5,16.7,25.1,26.5,120.9$, $128.5,135.9,136.8,197.7 \mathrm{ppm} ;{ }^{125} \mathrm{Te}$ NMR (126.2 MHz): $\delta=470 \mathrm{ppm}$.

1-[4-(Butyltellanyl)phenyl]ethanone (3d). Pale yellow oil, $45 \%$. $R_{f}(20 \%$ EtOAc/hexane): 0.74. IR (NaCl): $v=1261,1580,1676,2869,2925,2954$ $\mathrm{cm}^{-1} .{ }^{1} \mathrm{H}$ NMR $\left(\mathrm{CDCl}_{3}, 300.13 \mathrm{MHz}\right): \delta=0.91\left(\mathrm{t}, 3 \mathrm{H},{ }^{3} \mathrm{H}, \mathrm{H}=7.4 \mathrm{~Hz}\right), 1.37-$ $1.42(\mathrm{~m}, 2 \mathrm{H}), 1.76-1,86(\mathrm{~m}, 2 \mathrm{H}), 2.57(\mathrm{~s}, 3 \mathrm{H}), 2.97\left(\mathrm{t}, 3 \mathrm{H},{ }^{3} \mathrm{~J}_{\mathrm{H}, \mathrm{H}}=7.4 \mathrm{~Hz}\right)$ $7.72(\mathrm{~m}, 4 \mathrm{H}) \mathrm{ppm} ;{ }^{13} \mathrm{C} \mathrm{NMR}\left(\mathrm{CDCl}_{3}, 75.5 \mathrm{MHz}\right): \delta=8.8,13.5,25.2,26.6$, $33.8,121.0,128.6,135.9,136.7,197.8 \mathrm{ppm} ;{ }^{125} \mathrm{Te} \operatorname{NMR}(126.2 \mathrm{MHz}): \delta=$ $477 \mathrm{ppm}$.

1-[3-(Ethyltellanyl)phenyl]ethanone (3e). Pale yellow oil, $46 \%$. $R_{f}(20 \%$ EtOAc/hexane): 0.63. IR (NaCl): $v=1249,1562,1679,2860,2917,2953$ $\mathrm{cm}^{-1} .{ }^{1} \mathrm{H} \mathrm{NMR}\left(\mathrm{CDCl}_{3}, 300.13 \mathrm{MHz}\right): \delta=1.63\left(\mathrm{t}, 3 \mathrm{H},{ }^{3} \mathrm{JH}_{\mathrm{H}, \mathrm{H}}=7.6 \mathrm{~Hz}\right), 2.56$ $(\mathrm{s}, 3 \mathrm{H}) 2.89\left(\mathrm{q}, 2 \mathrm{H},{ }^{3} \mathrm{~J}_{\mathrm{H}, \mathrm{H}}=7.6 \mathrm{~Hz}\right), 7.27-7.28(\mathrm{~m}, 1 \mathrm{H}), 7.80-7.93(\mathrm{~m}, 1 \mathrm{H})$ $8.26(\mathrm{~s}, 1 \mathrm{H}) \mathrm{ppm} ;{ }^{13} \mathrm{C} \mathrm{NMR}\left(\mathrm{CDCl}_{3}, 75.5 \mathrm{MHz}\right): \delta=1.0,17.4,26.7,112.2$, 127.5, 129,2, 137.6, 137.9, 142.6, $197.6 \mathrm{ppm} ;{ }^{125} \mathrm{Te}$ NMR $(126.2 \mathrm{MHz}): \delta=$ $551 \mathrm{ppm}$.

1-[3-(Propyltellanyl)phenyl]ethanone (3f). Yellow oil, $43 \%$. $R_{f}(20 \%$ EtOAc/hexane): 0.46. IR ( $\mathrm{NaCl}): v=1249,1561,1680,2867,2925,2956$ 
$\mathrm{cm}^{-1} .{ }^{1} \mathrm{H} \mathrm{NMR}\left(\mathrm{CDCl}_{3}, 300.13 \mathrm{MHz}\right): \delta=0.98\left(\mathrm{t}, 3 \mathrm{H},{ }^{3} \mathrm{~J}_{\mathrm{H}, \mathrm{H}}=7.3 \mathrm{~Hz}\right), 1.82$ (sext, $\left.2 \mathrm{H},{ }^{3} \mathrm{~J}, H=7.4 \mathrm{~Hz}\right), 2.58(\mathrm{~s}, 3 \mathrm{H}), 2.93\left(\mathrm{t}, 3 \mathrm{H},{ }^{3} \mathrm{~J}_{\mathrm{H}, H}=7.4 \mathrm{~Hz}\right), 7.27(\mathrm{t}$, $\left.1 \mathrm{H},{ }^{3} \mathrm{~J}_{\mathrm{H}, \mathrm{H}}=7.7 \mathrm{~Hz}\right), 7.81-7.89(\mathrm{~m}, 2 \mathrm{H}), 8.27\left(\mathrm{t},{ }^{4} \mathrm{~J}_{\mathrm{H}, \mathrm{H}}=1.7 \mathrm{~Hz}, 1 \mathrm{H}\right) \mathrm{ppm}$; ${ }^{13} \mathrm{C} \mathrm{NMR}\left(\mathrm{CDCl}_{3}, 75.5 \mathrm{MHz}\right): \delta=11.8,16.7,25.1,26.7,112.4,127.5,129.2$ 137.7, 137.9, 142.6, $197.7 \mathrm{ppm} ;{ }^{125} \mathrm{Te}$ NMR (126.2 MHz): $\delta=479 \mathrm{ppm}$.

1-[3-(Butyltellanyl)phenyl]ethanone (3g). Pale yellow oil, $49 \%$. $R_{f}(20 \%$ EtOAc/hexane): 0.75. IR (NaCl): v= 1249, 1562, 1681, 2869, 2925, 2955 $\mathrm{cm}^{-1} .{ }^{1} \mathrm{H}$ NMR $\left(\mathrm{CDCl}_{3}, 300.13 \mathrm{MHz}\right): \delta=0.89\left(\mathrm{t}, 3 \mathrm{H},{ }^{3} \mathrm{JH}_{\mathrm{H}, \mathrm{H}}=7.3 \mathrm{~Hz}\right), 1.36-$ $1.43(\mathrm{~m}, 2 \mathrm{H}), 1.73-1.81(\mathrm{~m}, 2 \mathrm{H}), 2.58(\mathrm{~s}, 3 \mathrm{H}), 2.94\left(\mathrm{t}, 2 \mathrm{H},{ }^{3} \mathrm{~J}_{\mathrm{H}, \mathrm{H}}=7.6 \mathrm{~Hz}\right)$, 7.26-7.31 (m, 1H), 7.84-7.86 (m, 2H), 8.27 (s, 1H) ppm; ${ }^{13} \mathrm{C} \mathrm{NMR}\left(\mathrm{CDCl}_{3}\right.$, $75.5 \mathrm{MHz}$ ): $\delta=9.0,13.5,25.1,26.7,33.9,112.5,127.5,129.3,137.8,142.6$ $197.7 \mathrm{ppm}$; ${ }^{125} \mathrm{Te}$ NMR (126.2 MHz): $\delta=485 \mathrm{ppm}$.

\section{Synthesis of racemic alkyltellurium-1-phenylethanols $\mathbf{4 a - g}$}

$\mathrm{NaBH}_{4}(0.57 \mathrm{mg}, 1.5 \mathrm{mmol})$ was added in portions to a solution of the corresponding telluroketone $\mathbf{3 a - g}(1 \mathrm{mmol})$ in dry $\mathrm{MeOH}(2 \mathrm{~mL})$ under nitrogen atmosphere and $0{ }^{\circ} \mathrm{C}$. The mixture was left to warm until room temperature and stirred for $1 \mathrm{~h}$. Unreacted hydride excess was destroyed adding an aqueous $\mathrm{NH}_{4} \mathrm{Cl}$ saturated solution $(2 \mathrm{~mL})$, and then $\mathrm{MeOH}$ was evaporated in a rotary evaporator under reduced pressure. The mixture was extracted with $\mathrm{CH}_{2} \mathrm{Cl}_{2}(3 \times 10 \mathrm{~mL})$, combing the organic layers that were dried over $\mathrm{Na}_{2} \mathrm{SO}_{4}$, filtered and concentrated under reduced pressure. The reaction crude was purified by column chromatography on silica gel (20\% EtOAc/hexane), affording the corresponding racemic hydroxy tellurides $\mathbf{4 a - g}$ employed later for analytical purposes.

1-[4-(Methyltellanyl)phenyl]ethanol (4a). Pale yellow oil, $75 \%$. $R_{f}(20 \%$ EtOAc/hexane): 0.36; IR (NaCl): $v=1086,1111,1396,2925,2970,3370$ $\mathrm{cm}^{-1} .{ }^{1} \mathrm{H} \mathrm{NMR}\left(\mathrm{CDCl}_{3}, 300.13 \mathrm{MHz}\right): \delta=1.47\left(\mathrm{~d}, 3 \mathrm{H},{ }^{3} \mathrm{JH}, \mathrm{H}=6.3 \mathrm{~Hz}\right), 2.00$ (brs, $1 \mathrm{H}), 2.19(\mathrm{~s}, 3 \mathrm{H}), 4.85\left(\mathrm{q}, 1 \mathrm{H},{ }^{3} \mathrm{H}_{\mathrm{H}, \mathrm{H}}=6.3 \mathrm{~Hz}\right), 7.22\left(\mathrm{dd}, 2 \mathrm{H},{ }^{3} \mathrm{JHH}_{\mathrm{HH}}\right.$ $\left.7.9 \mathrm{~Hz},{ }^{4} \mathrm{JH}_{\mathrm{H}, \mathrm{H}}=1.8 \mathrm{~Hz}\right), 7.62\left(\mathrm{dd}, 2 \mathrm{H},{ }^{3} \mathrm{~J}_{\mathrm{H}, H}=7.9 \mathrm{~Hz},{ }^{4} \mathrm{~J}_{\mathrm{H}, H}=1.8 \mathrm{~Hz}\right) \mathrm{ppm}$; ${ }^{13} \mathrm{C} \mathrm{NMR}\left(\mathrm{CDCl}_{3}, 75.5 \mathrm{MHz}\right): \delta=-16.4,25.3,70.1,111.1,126.4,137.0$, $145.2 \mathrm{ppm} ;{ }^{125} \mathrm{Te}$ NMR (126.2 MHz): $\delta=326 \mathrm{ppm}$.

1-[4-(Ethyltellanyl)phenyl]ethanol (4b). Pale yellow oil, 92\%. $R_{f}(20 \%$ EtOAc/hexane): 0.36; IR (NaCl): $v=750,968,1009,2970,3324 \mathrm{~cm}^{-1} .{ }^{1} \mathrm{H}$ $\operatorname{NMR}\left(\mathrm{CDCl}_{3}, 300.13 \mathrm{MHz}\right): \delta=1.48\left(\mathrm{~d}, 3 \mathrm{H},{ }^{3} \mathrm{~J}_{\mathrm{H}, \mathrm{H}}=6.5 \mathrm{~Hz}\right), 1.65(\mathrm{t}, 2 \mathrm{H}$, $\left.{ }^{3} J_{H, H}=6.5 \mathrm{~Hz}\right), 1.92(\mathrm{brs}, 1 \mathrm{H}), 2.87\left(\mathrm{q}, 2 \mathrm{H},{ }^{3} \mathrm{~J}_{\mathrm{H}, \mathrm{H}}=7.6 \mathrm{~Hz}\right), 4.87(\mathrm{q}, 1 \mathrm{H}$ $\left.{ }^{3} \mathrm{JH}_{\mathrm{H}, \mathrm{H}}=7.6 \mathrm{~Hz}\right), 7.23\left(\mathrm{dd}, 2 \mathrm{H},{ }^{3} \mathrm{JH}_{\mathrm{H}, \mathrm{H}}=8.0 \mathrm{~Hz},{ }^{4} \mathrm{JH}_{\mathrm{H}, H}=1.9 \mathrm{~Hz}\right), 7.70(\mathrm{dd}, 2 \mathrm{H}$,

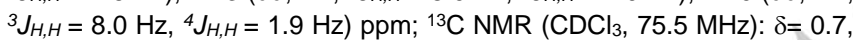
17.5, 25.3, 70.2, 110.4, 126.4, 138.7, 145.4 ppm; ${ }^{125} \mathrm{Te} \operatorname{NMR}(126.2 \mathrm{MHz})$ : $\delta=527 \mathrm{ppm}$.

1-[4-(Propyltellanyl)phenyl]ethanol (4c). Yellow oil, 70\%. $R_{f}(20 \%$ EtOAc/hexane): 0.45; IR (NaCl): $v=750,764,1274,2959,3324 \mathrm{~cm}^{-1} .{ }^{1} \mathrm{H}$ $\operatorname{NMR}\left(\mathrm{CDCl}_{3}, 300.13 \mathrm{MHz}\right): \delta=0.99\left(\mathrm{t}, 3 \mathrm{H},{ }^{3} \mathrm{~J}_{\mathrm{H}, H}=7.2 \mathrm{~Hz}\right), 1.47(\mathrm{~d}, 3 \mathrm{H}$, $\left.{ }^{3} \mathrm{~J}_{\mathrm{H}, \mathrm{H}}=6.5 \mathrm{~Hz}\right), 1.80\left(\mathrm{sext}, 2 \mathrm{H},{ }^{3} \mathrm{~J}_{\mathrm{H}, \mathrm{H}}=7.2 \mathrm{~Hz}\right), 1.93(\mathrm{brs}, \mathrm{OH}), 2.88(\mathrm{t}, 2 \mathrm{H}$, $\left.{ }^{3} J_{H, H}=7.2 \mathrm{~Hz}\right), 4.86\left(\mathrm{q}, 1 \mathrm{H},{ }^{3} J_{H, H}=6.5 \mathrm{~Hz}\right), 7.21\left(\mathrm{dd}, 2 \mathrm{H},{ }^{3} \mathrm{~J}_{H, H}=8.2 \mathrm{~Hz}\right.$, $\left.{ }^{4} J_{H, H}=1.9 \mathrm{~Hz}\right), 7.68\left(\mathrm{dd}, 2 \mathrm{H},{ }^{3} \mathrm{JH}_{H, H}=8.2 \mathrm{~Hz},{ }^{4} \mathrm{~J}_{H, H}=1.9 \mathrm{~Hz}\right) \mathrm{ppm} ;{ }^{13} \mathrm{C} \mathrm{NMR}$ $\left(\mathrm{CDCl}_{3}, 75.5 \mathrm{MHz}\right): \delta=11.4,16.7,25.2,25.3,70.2,110.5,126.4,138.6$, $145.4 \mathrm{ppm} ;{ }^{125} \mathrm{Te} \mathrm{NMR}(126.2 \mathrm{MHz}): \delta=454 \mathrm{ppm}$.

1-[4-(Butyltellanyl)phenyl]ethanol (4d). Pale yellow oil, $89 \%$. $R_{f}(10 \%$ EtOAc/hexane): 0.22; IR (NaCl): $v=764,1010,1261,2959,3336 \mathrm{~cm}^{-1} .{ }^{1} \mathrm{H}$ $\operatorname{NMR}\left(\mathrm{CDCl}_{3}, 300.13 \mathrm{MHz}\right): \delta=0.91\left(\mathrm{t}, 3 \mathrm{H},{ }^{3} \mathrm{~J}_{\mathrm{H}, \mathrm{H}}=7.2 \mathrm{~Hz}\right), 1.35-1.47(\mathrm{~m}$, $2 \mathrm{H}), 1.73\left(\mathrm{~d}, 3 \mathrm{H},{ }^{3} \mathrm{~J}_{\mathrm{H}, \mathrm{H}}=6.5\right), 1.78-1.80(\mathrm{~m}, 2 \mathrm{H}), 2.01(\mathrm{brs}, \mathrm{OH}), 2.89(\mathrm{t}$, $\left.2 \mathrm{H},{ }^{3} \mathrm{~J}_{\mathrm{H}, \mathrm{H}}=7.5 \mathrm{~Hz}\right), 4.85\left(\mathrm{q}, 1 \mathrm{H},{ }^{3} \mathrm{JH}, \mathrm{H}=6.5 \mathrm{~Hz}\right), 7.19\left(\mathrm{dd}, 2 \mathrm{H},{ }^{3} \mathrm{~J}_{\mathrm{H}, H}=8.3\right.$ $\left.\mathrm{Hz},{ }^{4} \mathrm{~J}_{\mathrm{H}, \mathrm{H}}=1.8 \mathrm{~Hz}\right), 7.68\left(\mathrm{dd}, 2 \mathrm{H},{ }^{3} \mathrm{~J}_{\mathrm{H}, \mathrm{H}}=8.3 \mathrm{~Hz},{ }^{4} \mathrm{~J}_{\mathrm{H}, \mathrm{H}}=1.8 \mathrm{~Hz}\right) \mathrm{ppm} ;{ }^{13} \mathrm{C}$ $\operatorname{NMR}\left(\mathrm{CDCl}_{3}, 75.5 \mathrm{MHz}\right): \delta=8.6,13.5,25.2,25.3,34.0,70.2,110.6,126.3$, 138.5, $145.3 \mathrm{ppm} ;{ }^{125} \mathrm{Te}$ NMR (126.2 MHz): $\delta=461 \mathrm{ppm}$.
1-[3-(Ethyltellanyl)phenyl]ethanol (4e). Pale yellow oil, $89 \%$. $R_{f}(20 \%$ EtOAc/hexane): 0.38; IR (NaCl): $v=697,764,1275,2969,3324 \mathrm{~cm}^{-1} .{ }^{1} \mathrm{H}$ $\operatorname{NMR}\left(\mathrm{CDCl}_{3}, 300.13 \mathrm{MHz}\right): \delta=1.48\left(\mathrm{~d}, 3 \mathrm{H},{ }^{3} \mathrm{~J}_{\mathrm{H}, H}=6.5 \mathrm{~Hz}\right), 1.66(\mathrm{t}, 2 \mathrm{H}$, $\left.{ }^{3} J_{H, H}=7.6 \mathrm{~Hz}\right), 2.89\left(\mathrm{q}, 2 \mathrm{H},{ }^{3} \mathrm{~J}_{\mathrm{H}, \mathrm{H}}=7.6 \mathrm{~Hz}\right), 4.84\left(\mathrm{q}, 1 \mathrm{H},{ }^{3} \mathrm{~J}_{\mathrm{H}, H}=6.5 \mathrm{~Hz}\right)$, 7.16-7.21 (m, 1H), 7.26-7.29 (m, 1H), 7.59-7.62 (m, 1H), $7.72(\mathrm{~s}, 1 \mathrm{H})$ $\mathrm{ppm} ;{ }^{13} \mathrm{C} \mathrm{NMR}\left(\mathrm{CDCl}_{3}, 75.5 \mathrm{MHz}\right): \delta=1.2,17.3,25.3,70.2,112.0,124.8$, 129.3, 135.4, 137.4, 146.8 ppm; ${ }^{125} \mathrm{Te}$ NMR (126.2 MHz): $\delta=534$ ppm.

1-[3-(Propyltellanyl)phenyl)ethanol (4f). Yellow oil, 79\%. $R_{f}(20 \%$ EtOAc/hexane): 0.50. IR (NaCl): $v=697,764,1267,2959,3323 \mathrm{~cm}^{-1} .{ }^{1} \mathrm{H}$ NMR $\left(\mathrm{CDCl}_{3}, 300.13 \mathrm{MHz}\right): \delta=0.99\left(\mathrm{t}, 3 \mathrm{H},{ }^{3} \mathrm{JH}_{\mathrm{H}, \mathrm{H}}=7.4 \mathrm{~Hz}\right), 1.48(\mathrm{~d}, 3 \mathrm{H}$, $\left.{ }^{3} J_{H, H}=6.5\right), 1.82$ (sext, $2 \mathrm{H},{ }^{3} \mathrm{JH}_{\mathrm{H}, H}=7.4 \mathrm{~Hz}$ ), 1.94 (brs, OH), $2.90\left(\mathrm{t}, 2 \mathrm{H},{ }^{3} \mathrm{JH}_{\mathrm{H}, \mathrm{H}}\right.$ $=7.4 \mathrm{~Hz}), 4.84\left(\mathrm{q}, 1 \mathrm{H},{ }^{3} \mathrm{~J}_{\mathrm{H}, \mathrm{H}}=6.5 \mathrm{~Hz}\right), 7.15-7.20(\mathrm{~m}, 1 \mathrm{H}), 7.28-7.29(\mathrm{~m}$, $1 \mathrm{H}), 7.58-7.61(\mathrm{~m}, 1 \mathrm{H}), 7.72(\mathrm{~s}, 1 \mathrm{H}) \mathrm{ppm} ;{ }^{13} \mathrm{C} \mathrm{NMR}\left(\mathrm{CDCl}_{3}, 75.5 \mathrm{MHz}\right): \delta=$ $11.4,16.8,25.2,25.3,70.2,112.0,124.7,129.3,135.3,137.2,146.7$ ppm; ${ }^{125} \mathrm{Te}$ NMR $(126.2 \mathrm{MHz}): \delta=469 \mathrm{ppm}$.

1-[3-(Butyltellanyl)phenyl]ethanol (4g). Pale yellow oil, $35 \% . R_{f}(20 \%$ EtOAc/hexane): 0.56. IR (NaCl): $v=698,1064,1267,2956,3334 \mathrm{~cm}^{-1} .{ }^{1} \mathrm{H}$ $\operatorname{NMR}\left(\mathrm{CDCl}_{3}, 300.13 \mathrm{MHz}\right): \delta=0.90\left(\mathrm{t}, 3 \mathrm{H},{ }^{3} \mathrm{JH}, \mathrm{H}=7.3 \mathrm{~Hz}\right), 1.38-1.41(\mathrm{~m}$, $2 \mathrm{H}), 1.47\left(\mathrm{~d}, 3 \mathrm{H},{ }^{3} \mathrm{~J}_{\mathrm{H}, \mathrm{H}}=6.3 \mathrm{~Hz}\right), 1.76-1.79(\mathrm{~m}, 2 \mathrm{H}), 2.04$ (brs, $\left.1 \mathrm{H}\right), 2.91$ $\left(\mathrm{t}, 2 \mathrm{H},{ }^{3} \mathrm{JH}_{\mathrm{H}, \mathrm{H}}=7.7 \mathrm{~Hz}\right), 4.83\left(\mathrm{q}, 1 \mathrm{H},{ }^{3} \mathrm{~J}_{\mathrm{H}, \mathrm{H}}=6.3 \mathrm{~Hz}\right), 7.17\left(\mathrm{t}, 2 \mathrm{H},{ }^{3} \mathrm{~J}_{\mathrm{H}, H}=7.4\right.$ $\mathrm{Hz}), 7.36-7.61(\mathrm{~m}, 1 \mathrm{H}), 7.70(\mathrm{~s}, 1 \mathrm{H}) \mathrm{ppm} ;{ }^{13} \mathrm{C} \mathrm{NMR}\left(\mathrm{CDCl}_{3}, 75.5 \mathrm{MHz}\right): \delta=$ 8.6, 13.5, 25.2, 25.3, 34.0, 70.1, 124.7, 129.3, 135.2, 137.2, 146.7 ppm; ${ }^{125} \mathrm{Te} \operatorname{NMR}(126.2 \mathrm{MHz}): \delta=462 \mathrm{ppm}$.

\section{Bioreduction experiments}

$\mathrm{ADH}$-catalyzed reduction experiments were performed in aqueous medium ( $50 \mathrm{mmol} \mathrm{L}{ }^{-1}$ Tris. $\mathrm{HCl}$ buffer $\mathrm{pH} 7.5$ ) using a small quantity of dimethylsulfoxide (DMSO, $2.5 \% \mathrm{v} / \mathrm{v}$ ) as cosolvent aiming the solubilization of telluroketones in aqueous media, all of them containing catalytic amounts of $\mathrm{NAD}^{+}$or $\mathrm{NADP}^{+}\left(10 \mathrm{mmol} \mathrm{L}{ }^{-1}\right)$ depending on the enzyme cofactor dependency at $30^{\circ} \mathrm{C}$ for $24 \mathrm{~h}$. For cofactor regeneration purposes, the usual substrate-coupled method was employed, in which 2-propanol ( $\mathrm{PrOH}, 5 \% \mathrm{v} / \mathrm{v}$ ) acted as co-substrate and co-solvent, except for Ras-ADH that used the enzyme-coupled approach with glucose and glucose dehydrogenase.

\section{Bioreduction mediated by E. coli/Ras-ADH}

Lyophilized cells of $E$. coli/Ras-ADH (12 mg), DMSO (15 $\mu \mathrm{L}, 2.5 \% \mathrm{v} / \mathrm{v}), 1$ $\mathrm{mmol} \mathrm{L}^{-1} \mathrm{NADP}^{+}\left(60 \mu \mathrm{L}\right.$ of a $10 \mathrm{mmol} \mathrm{L}^{-1}$ stock solution), $50 \mathrm{mmol} \mathrm{L}-1$ glucose $\left(60 \mu \mathrm{L}\right.$ of a $500 \mathrm{mmol} \mathrm{\textrm {L } ^ { - 1 }}$ stock solution) and glucose dehydrogenase $(10 \mathrm{U})$ were added into an Eppendorf tube containing telluroketones 3a-g $\left(25 \mathrm{mmol} \mathrm{L}^{-1}\right)$ in a $50 \mathrm{mmol} \mathrm{L}^{-1}$ Tris. $\mathrm{HCl}$ buffer $\mathrm{pH} 7.5$ $(420 \mu \mathrm{L})$. The reaction was shaken at $30^{\circ} \mathrm{C}$ and $250 \mathrm{rpm}$ for $24 \mathrm{~h}$, and after this time, the mixture was extracted with ethyl acetate $(3 \times 500 \mu \mathrm{L})$. The organic layers were separated by centrifugation ( $2 \mathrm{~min}, 5700 \mathrm{rpm}$ ), combined and finally dried over $\mathrm{Na}_{2} \mathrm{SO}_{4}$. An aliquot was taken to inject in the GC for the measurement of conversion and enantiomeric excess values.

\section{Bioreduction mediated by E. coli/Lb-ADH}

Lyophilized cells of E. coli/Lb-ADH (12 mg), ${ }^{i} \mathrm{PrOH}(30 \mu \mathrm{L}, 5 \% \mathrm{v} / \mathrm{v}), 1 \mathrm{mmol}$ $\mathrm{L}^{-1} \mathrm{NADP}^{+}\left(60 \mu \mathrm{L}\right.$ of a $10 \mathrm{mmol} \mathrm{L}^{-1}$ stock solution) and $10 \mathrm{mmol} \mathrm{L}^{-1} \mathrm{MgCl}_{2}$ ( $60 \mu \mathrm{L}$ of a $100 \mathrm{mmol} \mathrm{L}^{-1}$ stock solution) were added into an Eppendorf tube containing telluroketones $3 \mathrm{a}-\mathrm{g}\left(25 \mathrm{mmol} \mathrm{L}^{-1}\right)$ in a $50 \mathrm{mmol} \mathrm{L}^{-1} \mathrm{Tris} \cdot \mathrm{HCl}$ buffer pH $7.5(480 \mu \mathrm{L})$. The reaction was shaken at $30^{\circ} \mathrm{C}$ and $250 \mathrm{rpm}$ for $24 \mathrm{~h}$, and after this time, the mixture was extracted with ethyl acetate $(3 \mathrm{x}$ $500 \mu \mathrm{L}$ ). The organic layers were separated by centrifugation ( $2 \mathrm{~min}, 5700$ 
rpm), combined and finally dried over $\mathrm{Na}_{2} \mathrm{SO}_{4}$. An aliquot was taken to inject in the GC for the measurement of conversion and enantiomeric excess values.

Bioreduction mediated by E. coli/Sy-ADH, E. coli/TeS-ADH and E. coli/ADH-T

Lyophilized cells of E. coli/ADH (12 mg), $\operatorname{PrOH}(30 \mu \mathrm{L}, 5 \% \mathrm{v} / \mathrm{v})$ and $1 \mathrm{mmol}$ $\mathrm{L}^{-1} \mathrm{NADP}^{+}\left(60 \mu \mathrm{L}\right.$ of a $10 \mathrm{mmol} \mathrm{L}{ }^{-1}$ stock solution) were added into an Eppendorf tube containing telluroketones $3 \mathrm{a}-\mathrm{g}\left(25 \mathrm{mmol} \mathrm{L}^{-1}\right)$ in a $50 \mathrm{mmol}$ $\mathrm{L}^{-1}$ Tris $\mathrm{HCl}$ buffer $\mathrm{pH} 7.5(510 \mu \mathrm{L})$. The reaction was shaken at $30^{\circ} \mathrm{C}$ and $250 \mathrm{rpm}$ for $24 \mathrm{~h}$, and after this time, the mixture was extracted with ethy acetate $(3 \times 500 \mu \mathrm{L})$. The organic layers were separated by centrifugation (2 min, $5700 \mathrm{rpm}$ ), combined and finally dried over $\mathrm{Na}_{2} \mathrm{SO}_{4}$. An aliquot was taken to inject in the GC for the measurement of conversion and enantiomeric excess values.

\section{Bioreduction mediated by E. coli/ADH-A}

Lyophilized cells of E. coli/ADH-A (12 mg), $\operatorname{PrOH}(30 \mu \mathrm{L}, 5 \% \mathrm{v} / \mathrm{v})$ and 1 mmol L-1 NAD $\left(60 \mu \mathrm{L}\right.$ of a $10 \mathrm{mmol} \mathrm{L}^{-1}$ stock solution) were added into an Eppendorf tube containing telluroketones 3a-g $\left(25 \mathrm{mmol} \mathrm{L}^{-1}\right)$ in a $50 \mathrm{mM}$ Tris $\mathrm{HCl}$ buffer $\mathrm{pH} 7.5(510 \mu \mathrm{L})$. The reaction was shaken at $30^{\circ} \mathrm{C}$ and 250 rpm for $24 \mathrm{~h}$, and after this time, the mixture was extracted with ethyl acetate $(3 \times 500 \mu \mathrm{L})$. The organic layers were separated by centrifugation (2 min, $5700 \mathrm{rpm}$ ), combined and finally dried over $\mathrm{Na}_{2} \mathrm{SO}_{4}$. An aliquot was taken to inject in the GC for the measurement of conversion and enantiomeric excess values.

\section{Bioreduction mediated by evo-1.1.200}

Commercially available evo-1.1.200 (10 mg), $\operatorname{PrOH}(25 \mu \mathrm{L}, 5 \% \mathrm{v} / \mathrm{v}), 1$ mmol L-1 NAD ${ }^{+}\left(50 \mu \mathrm{L}\right.$ of a $10 \mathrm{mmol} \mathrm{L}^{-1}$ stock solution) and $10 \mathrm{mmol} \mathrm{L}^{-1}$ $\mathrm{MgCl}_{2}$ (50 $\mu \mathrm{L}$ of a $100 \mathrm{mmol} \mathrm{L}^{-1}$ stock solution) were added into an Eppendorf tube containing telluroketones 3a-g $\left(25 \mathrm{mmol} \mathrm{L}^{-1}\right)$ in a $50 \mathrm{mM}$ Tris $\mathrm{HCl}$ buffer $\mathrm{pH} 7.5(325 \mu \mathrm{L})$. The reaction was shaken at $30^{\circ} \mathrm{C}$ and 250 rpm for $24 \mathrm{~h}$, and after this time, the mixture was extracted with ethyl acetate $(3 \times 500 \mu \mathrm{L})$. The organic layers were separated by centrifugation (2 min, $5700 \mathrm{rpm}$ ), combined and finally dried over $\mathrm{Na}_{2} \mathrm{SO}_{4}$. An aliquot was taken to inject in the GC for the measurement of conversion and enantiomeric excess values.

Derivatization of optically active hydroxy tellurides (4a-g) into 1phenylethanol for enantiomeric excess measurements

Enantiomeric excesses (ee) values were determined using an Agilent 6890A GC-system equipped with a chiral stationary phase Chirasil $\beta$-Dex column $(25 \mathrm{~m} \times 0.25 \mathrm{~mm}, 0.25 \mu \mathrm{m})$, after treatment of the hydroxy telluride samples with "BuLi for the removal of the tellurium moiety ("TeR") at the aromatic ring. For this purpose, a solution of 'BuLi in pentane $1.9 \mathrm{mmol} \mathrm{L}$ ' ${ }^{1}(0.195 \mathrm{mmol}, 100 \mu \mathrm{L})$ was added dropwise to a solution of optically active hydroxy telluride 4a-g (approximately $0.015 \mathrm{mmol}$ ) in dry THF $(200 \mu \mathrm{L})$ under nitrogen atmosphere at $-78^{\circ} \mathrm{C}$. The mixture was left to warm until $0^{\circ} \mathrm{C}$ and stirred for $2 \mathrm{~h}$ and after this period unreacted 'BuLi was destroyed adding brine $(300 \mu \mathrm{L})$. The mixture was extracted with EtOAc $(2 \times 250 \mu \mathrm{L})$, the organic layers separated by centrifugation ( $1 \mathrm{~min}, 5700 \mathrm{rpm}$ ), combined and finally dried over $\mathrm{Na}_{2} \mathrm{SO}_{4}$. Then, an aliquot was promptly analyzed in the GC (see the Supporting Information for further details).

Semi-preparative bioreduction of $3 b$ into $(S)-4 b$ mediated by RasADH
Lyophilized cells of $E$. coli//Ras-ADH (290 mg), DMSO (362 $\mu \mathrm{L}, 2.5 \% \mathrm{v} / \mathrm{v})$ $1 \mathrm{mmol} \mathrm{L}^{-1} \mathrm{NADP}^{+}\left(1.45 \mathrm{~mL}\right.$ of a $10 \mathrm{mmol} \mathrm{L}^{-1}$ stock solution), $50 \mathrm{mmol} \mathrm{L}^{-1}$ glucose $\left(1.45 \mathrm{~mL}\right.$ of a $500 \mathrm{mmol} \mathrm{L} \mathrm{L}^{-1}$ stock solution) and glucose dehydrogenase $(10 \mathrm{U})$ were added into an Erlenmeyer flask containing telluro-acetophenone $\mathbf{3 b}\left(100 \mathrm{mg}, 0.36 \mathrm{mmol}, 25 \mathrm{mmol} \mathrm{L}^{-1}\right)$ in a $50 \mathrm{mmol}$ $\mathrm{L}^{-1}$ Tris $\mathrm{HCl}$ buffer $\mathrm{pH} 7.5(10 \mathrm{~mL})$. The reaction was shaken at $30^{\circ} \mathrm{C}$ and $250 \mathrm{rpm}$ for $24 \mathrm{~h}$, and after this time, the mixture was extracted with ethyl acetate $(3 \times 500 \mu \mathrm{L})$. The organic layers were combined, dried over $\mathrm{Na}_{2} \mathrm{SO}_{4}$ and filtered. The resulting reaction crude was purified by column chromatography on silica gel (20\% EtOAc/hexane), affording (S)-(-)-4b $\left[42 \%\right.$ isolated yield and $\left.>99 \% \mathrm{ee},[\alpha]_{\mathrm{D}}^{20}=-10.2\left(\mathrm{c}=2.0, \mathrm{CHCl}_{3}\right)\right]$.

\section{Acknowledgments}

The authors thank the national Council for Scientific and Technological Development (CNPq, Brazil, Proc. 456834/2014), the Coordination for the Improvement of Higher Level Personnel (CAPES, Brazil), the Spanish Ministry of Economy and Competitiveness (MINECO, CTQ-2013-44153-P project) and the Government of the Principado de Asturias (FC-GRUPINIDI/2018/000181) for financial supports. P. T. B thanks CAPES for her PDSE felowship (Edital $N^{\circ}$ 47/2017). Prof. Wolfgang Kroutil is also acknowledged for the donation of overexpressed alcohol dehydrogenases.

Keywords: - Alcohol dehydrogenases - Asymmetric synthesis Enzyme catalysis $\bullet$ Optically active organotellurides $•$ Tellurium

[1] T. Chivers, R. S. Laitinen, Chem. Soc. Rev. 2015, 44, 1725-1739.

[2] a) R. E. Barrientos-Astigarraga, P. Castelani, J. V. Comasseto, H. B. Formiga, N. C. da Silva, C. Y. Sumida, M. L. J. Vieira, J. Organomet Chem. 2001, 623, 43-47; b) H. A. Stefani, J. M. Pena, F. Manarin, R. A Ando, D. M. Leal, N. Petragnani, Tetrahedron Lett. 2011, 52, 4398-4401.

[3] N. Petragnani, H. A. Stefani in Tellurium in Organic Synthesis, 2nd Ed. Academic Press, London, 2007, pp. 115-283.

[4] a) J. Gu, Z. Q. Zhao, Y. Ding, H. L. Chen, Y. W. Zhang, C. H. Yan, J. Am Chem. Soc. 2013, 135, 8363-8371; b) F. M. Makuei, G. Senanayake, Miner. Eng. 2018, 115, 79-87.

[5] a) C. W. Nogueira, G. Zeni, J. B. T. Rocha, Chem. Rev. 2004, 104, 6255 6285 ; b) R. L. O. R. Cunha, I. E. Gouvea, L. Juliano, An. Acad. Bras. Cienc. 2009, 81, 393-407; c) L. A. Ba, M. Doring, V. Jamier, J. Jacob, Org. Biomol. Chem. 2010, 8, 4203-4216.

[6] a) M. R. Detty, A. E. Friedman, A. R. Oserof, J. Org. Chem. 1994, 59, $8245-8250$; b) C. B. C. Lima, W. W. Arrais-Silva, R. L. O. R. Cunha, S Giorgio, Korean J. Parasitol. 2009, 47, 213-218; c) I. A. S. Pimentel, C. S. Paladi, S. Katz, W. A. S. Judice, R. L. O. R. Cunha, C. Barbiéri, PLoS One 2012, 7, e48780-7; d) J-F. Poon, J. Yan, V. P. Singh, P. J. Gates, L. Engman, J. Org. Chem. 2016, 81, 12540-12544; e) L. F. R. Sá, F. T. Toledo, A. C. Gonçalves, B. A. Sousa, A. A. dos Santos, P. F. Brasil, V. A. D. da Silva, A. C. Tessis, J. A. Ramos, M. A. Carvalho, E. Lamping, A. Ferreira-Pereira, Antimicrob. Agents Chemother. 2017, 61, e0123116; f) W. Hou, Y. Zhou, J. Rui, R. Bai, A. K. K. Bhasin, B. H. Ruan, Bioorg. Med. Chem. Lett. 2019, 29, 1673-1676. g) P. T. Bandeira, M. C. Dalmolin M. M. de Oliveira, K. C. Nunes, F. P. Garcia, C. V. Nakamura, C. V.; A R. M. de Oliveira, L. Piovan, Bioorg. Med. Chem. 2019, 2, 410-415

[7] a) P. Ferraboschi, P. Grisenti, E. Santaniello, Synlett 1990, 545-546; b) T. Izumi, T. Nakamura, Y. Eda, J. Chem. Tech. Biotechnol. 1993, 57 175-180; c) T. Izumi, Y. Eda, J. Chem. Tech. Biotechnol. 1995, 62, $25-$ 29; d) C. E. Costa, G. C. Clososki, H. B. Barchesi, S. P. Zanotto, M. G Nascimento, J. V. Comasseto, Tetrahedron: Asymmetry 2004, 15, 3945- 
3954; e) L. H. Andrade, A. T. Omori, A. L. M. Porto, J. V. Comasseto, J Mol. Catal. B: Enzym. 2004, 29, 47-54; f) J. V. Comasseto, A. T. Omori, A. L. M. Porto, L. H. Andrade, Tetrahedron Lett. 2004, 45, 473-476; g) M. Gruttadauria, P. L. Meo, S. Riela, F. D'Anna, R. Noto, Tetrahedron Asymmetry 2006, 17, 2713-2721; h) A. T. Omori, L. F. Assis, L. H. Andrade, J. V. Comasseto, A. L. M. Porto, Tetrahedron: Asymmetry 2007 18, 1048-1053; i) L. F. Assis, E. Kagohara, A. T. Omori, J. V. Comasseto, L. H. Andrade, A. L. M. Porto, Food Technol. Biotechnol. 2007, 45, 415 419; j) L. Piovan, M. Capelari, L. H. Andrade, J. V. Comasseto, A. L. M. Porto, Tetrahedron: Asymmetry 2007, 18, 1398-1402; k) L. H. Andrade, Silva, A. V. Tetrahedron: Asymmetry 2008, 19, 1175-1181; I) L. H. Andrade, A. V. Silva, E. C. Pedrozo, Tetrahedron Lett. 2009, 50, 43314334.

[8] a) A. A. dos Santos, C. E. da Costa, J. L. Princival, J. V. Comasseto, Tetrahedron: Asymmetry 2006, 17, 2252-2259; b) R. Ferrarini, J. V Comasseto, A. A. dos Santos, Tetrahedron: Asymmetry 2009, 20, 20432047 ; c) R. A. Gariani, F. A. G. Luengo, L. A. S. Vale, R. C. Bazito, J. V. Comasseto, Tetrahedron Lett. 2011, 52, 3336-3338.

[9] a) B. K. Bassora, C. E. da Costa, R. A. Gariani, J. V. Comasseto, A. A. dos Santos, Tetrahedron Lett. 2007, 48, 1485-1487; b) J. V. Comasseto, R. A. Gariani, Tetrahedron 2009, 65, 8447-8459.

[10] A. A. dos Santos, J. L. Princival, J. V. Comasseto, S. M. G. Barros, J. E. B. Neto, Tetrahedron 2007, 63, 5167-5172.

[11] a) Y. You, K. Ahsan, M. R. Detty, J. Am. Chem. Soc. 2003, 125, 4918 4927; b) L. Piovan, L. Wu, Z-Y. Zhang, L. H. Andrade, Org. Biomol. Chem. 2011, 9, 1347-1351; c) L. Piovan, M. F. M. Alves, L. Juliano, D. Bromme R. L. O. R. Cunha, L. H. Andrade, Bioorg. Med. Chem. 2011, 19, 2009 2014; d) E. L. Borges, M. T. Ignasiak, Y. Velichenko, G. Perin, C. A Hutton, M. J. Davies, C. H. Schiesser, Chem. Commun. 2018, 54, $2990-$ 2993; e) D. Tanini, A. Capperucci, C. T. Supuran, A. Angeli, Bioorg. Chem. 2019, 87, 516-522; f) D. Tanini, C. Borgogni, A. Capperucci, New J. Chem. 2019, 43, 6388-6393; g) L. Piovan, P. Milani, M. Silva, P. G. Moraes, M. Demasi, L. H. Andrade, Eur. J. Med. Chem. 2014, 73, 280 285; h) T. Paschoalin, A. A. Martens, A. T. Omori,F. V. Pereira, L. Juliano, L. R. Travassos, G. M. Machado-Santelli, R. L. O. R. Cunha, Bioorg. Med. Chem. 2019, 27, 2537-2545.

[12] a) J. Albarrán-Velo, D. González-Martínez, V. Gotor-Fernández, Biocatal. Biotransf. 2018, 36, 102-130; b) J. Chapman, A. E. Ismail, C. Z. Dinu Catalysts 2018, 8, 238; c) J. P. Adams, M. J. B. Brown, A. DiazRodriguez, R. C. Lloyd, G.-D. Roiban, Adv. Synth. Catal. 2019, 361 2421-2432; d) A. M. Foley, A. R. Maguire, Eur. J. Org. Chem. 2019,
3713-3734; e) R. A. Sheldon, D. Brady, ChemSusChem 2019, 12, 2859 2881

[13] a) M. Breuer, K. Ditrich, T. Habicher, B. Hauer, M. Keßeler, R. Stürmer, T. Zelinski, Angew. Chem. Int. Chem. 2004, 43, 788-824; b) M. Hall, A S. Bommarius, Chem. Rev. 2011, 111, 4088-4110; c) Y-G. Zheng, H-H. Yin, D-F. Yu, X. Chen, X-L. Tang, X-J. Zhang, Y-P. Xue, Y-J. Wang, Z Q. Liu, Appl. Microbiol. Biotechnol. 2017, 101, 987-1001; d) J. Ana, Y. Niea, Y. Xua, Crit. Rev. Biotechnol. 2019, 39, 366-379; e) C. K. Prier, B. Kosjek, Curr. Opin. Chem. Biol. 2019, 49, 105-112.

[14] Wang, X. Wu, Z. Li, Z. Huang, F. Chen, Org. Biomol. Chem. 2019, 17 3575-3580.

[15] D. Méndez-Sánchez, Á. Mourelle-Insua, V. Gotor-Fernández, I. Lavandera, Adv. Synth. Catal. 2019, 361, 2706-2712.

[16] K. Kędziora, F. R. Bisogno, I. Lavandera, V. Gotor-Fernández, J. Montejo-Bernardo, S. García-Granda, W. Kroutil, V. Gotor, ChemCatChem 2014, 6, 1066-1072.

[17] R. E.; Maguire, A. R. Eur. J. Org. Chem. 2014, 3737-3756.

[18] T. Barcellos, K. Tauber, W. Kroutil, L. H. Andrade, Tetrahedron: Asymmetry 2011, 22, 1772-1777.

[19] K. Nakamura, R. Yamanaka, T. Matsuda, T. Harada, Tetrahedron: Asymmetry 2003, 14, 2659-2681.

[20] M. C. Dalmolin, P. T. Bandeira, M. S. Ferri, A. R. M. de Oliveira, L. Piovan, J. Organomet. Chem. 2018, 874, 32-39.

[21] À. Mourelle-Insua, G. de Gonzalo, I. Lavandera, V. Gotor-Fernández, Catalysts 2018, 8, 150 .

[22] I. Lavandera, A. Kern, B. Ferreira-Silva, A. Glieder, S. de Wildeman, W. Kroutil, J. Org. Chem. 2008, 73, 6003-6005.

[23] S. Leuchs, L. Greiner, Chem. Biochem. Eng. Q. 2011, 25, 267-281.

[24] I. Lavandera, A. Kern, V. Resch, B. Ferreira-Silva, A. Glieder, W. M. F. Fabian, S. de Wildeman, W. Kroutil, Org. Lett. 2008, 10, 2155-2158.

[25] C. Heiss, M. Laivenieks, J. G. Zeikus, R. S. Phillips, Bioorg. Med. Chem. 2001, 9, 1659-1666.

[26] J. Peters, T. Minuth, M.-R. Kula, Enzyme Microb. Technol. 1993, 11, 950 958.

[27] W. Stampfer, B. Kosjek, C. Moitzi, W. Kroutil, K. Faber, Angew. Chem Int. Ed. 2002, 41, 1014-1017.

[28] P. Könst, H. Merkens, S. Kara, S. Kochius, A. Vogel, R. Zuhse, D. Holtmann, I. W. C. E. Arends, F. Hollmann, Angew. Chem. Int. Ed. 2012, 51, 9914-9917. 
WILEY-VCH

\section{FULL PAPER}<smiles>CC(=O)c1[R10]ccc1</smiles>

$\mathrm{R}=\mathrm{Me}, \mathrm{Et},{ }^{{ }^{\mathrm{Pr}},{ }^{n} \mathrm{Bu}}$

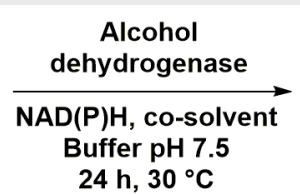

RTe<smiles>C[C@@H](O)c1ccccc1</smiles>

ee up to $>99 \%$

\section{Tellurium chemistry}

Pamela Taisline Bandeira, Vicente Gotor-Fernández, * and Leandro Piovan*

Page No. - Page No.

Stereoselective Bioreduction of Telluro-acetophenones to Optically Active Hydroxy Tellurides

A series of telluro-acetophenones has been chemically synthesized and later reduced using alcohol dehydrogenases of complementary selectivity. Therefore, $(R)$ and $(S)$-hydroxy tellurides have been obtained in good to excellent optical purities under mild reaction conditions in aqueous medium. 